\title{
Morfoanatomia da flor de cinco espécies de Galipea Aubl. e seu significado na evolução de flores tubulosas entre as Rutaceae neotropicais
}

\author{
JOSÉ RUBENS PIRANI ${ }^{1,2}$, JULIANA HANNA LEITE EL OTTRA ${ }^{1} \mathrm{e}$ \\ NANUZA LUIZA DE MENEZES ${ }^{1}$
}

(recebido: 11 de março de 2009; aceito: 25 de março de 2010)

\begin{abstract}
Floral morphology and anatomy of five species of Galipea Aubl. and its bearing on the evolution of tubular flowers in Neotropical Rutaceae). Most genera of the neotropical subtribe Galipeinae (tribe Galipeeae, Rutoideae) have tubular flowers with several forms and degrees of fusion between parts. The fact that Galipea and other genera in the subtribe bear only two fertile anthers plus five or more staminodes is also intriguing, since generally the Galipeeae exhibit isostemony. To elucidate the anatomic condition of these traits, and to establish an accurate coding scheme for characters state in phylogenetic studies, a morphoanatomical study of the flower of five species of Galipea was carried out. Using cross-sections of pickled material, the patterns of vascularization, position, and union of the flower segments were investigated. Noteworthy results are: 1) a true floral tube is formed in the basal third part of the flower through the connation of filaments and the adnation of this staminal tube to the petals; 2) the petals are distally coherent to each other and adherent to the filaments by means of capillinection (close intertwining of trichomes) - a case of pseudosympetaly; 3) from the usually five linear structures referred to as staminodes, only the three external ones are homologous to fully sterilized stamens, while the other ones arise as branches from the petals; 4) carpels are congenitally connate axially and laterally, except for a small area close to the top of the ovary where they are postgenitally united; 5) the vascularization of the disc suggests a receptacular origin. The implications of these data for the evolution of tubular flowers in Galipea and related groups are discussed.
\end{abstract}

Key words - floral anatomy, pseudosympetaly, Sapindales, staminodes, tubular flowers

RESUMO - (Morfoanatomia da flor de cinco espécies de Galipea Aubl. e seu significado na evolução de flores tubulosas entre as Rutaceae neotropicais). A maioria dos gêneros da subtribo neotropical Galipeinae (tribo Galipeeae, Rutoideae) tem flores tubulosas, com várias formas e graus de conação e adnação. Galipea e outros gêneros na subtribo apresentam apenas duas anteras férteis mais cinco ou mais estaminódios, o que é intrigante porque na tribo predominam flores pentâmeras isostêmones. Visando elucidar a condição anatômica dessas características e estabelecer estados acurados para caracteres em análises filogenéticas, um estudo morfoanatômico de flores de cinco espécies de Galipea foi realizado, buscando os padrões de vascularização, posição, e união dos segmentos da flor. Destacam-se os resultados: 1) um tubo floral genuíno se forma no terço basal da flor por conação dos filetes e adnação desse tubo estaminal às pétalas; 2) as pétalas são distalmente coerentes umas às outras e aderentes aos filetes por meio de entrelaçamento de tricomas densos - um caso de pseudossimpetalia; 3) dentre as cinco (às vezes seis) estruturas tratadas como estaminódios, apenas as três externas são de fato homólogas a estames esterilizados, as demais surgem como ramificações adaxiais das pétalas; 4) os carpelos são peltados, congenitalmente conatos axial e lateralmente da base do ovário até o nível das placentas, e no estilete e estigma; na zona mediana e superior do ovário eles são unidos apenas posgenitalmente, com a epiderme diferenciada de carpelos contíguos e suturas evidentes na região ventral de cada carpelo; 5) a vascularização do disco sugere origem receptacular. As implicações desses dados para o entendimento da evolução das flores tubulosas em Galipea e grupos relacionados são discutidas.

Palavras-chave - anatomia floral, estaminódios, flores tubulosas, pseudossimpetalia, Sapindales

\section{Introdução}

Na família Rutaceae, existe uma grande diversidade de tipos florais, e a investigação morfológica e anatômica em vários gêneros tem revelado aspectos importantes para a biologia, taxonomia, filogenia e evolução. Versando sobre anatomia floral, podem ser mencionados

1. Universidade de São Paulo, Instituto de Biociências, Departamento de Botânica, Rua do Matão, 277, 05508-090 São Paulo, SP, Brasil.

2._Autor para correspondência: pirani@usp.br os trabalhos de Tillson \& Bamford (1938) e de Ford (1942), sobre espécies do grupo das frutas cítricas (subfamília Aurantioideae); de Hartl (1957) sobre Correa Andrews; de Gut (1966) sobre eixo floral e gineceu de treze gêneros das subfamílias Rutoideae, Toddaliodeae e Aurantioideae; de Tilak \& Nene (1976, 1978), sobre a origem do disco e vascularização floral em dez espécies asiáticas da família; de Yamasaki (1988) sobre espécies asiáticas de Zanthoxylum L.; de Ramp (1988) sobre o gineceu de 57 espécies de 30 gêneros da família.

Com espécies brasileiras, destacam-se os trabalhos de Gut (1966), que trata do gineceu de Pilocarpus 
pennatifolius Lem., de Marquete (1981), descrevendo a anatomia e vascularização da flor de Pilocarpus organensis Occhioni \& Rizzini (= P. pauciflorus A. St.-Hil.), o de Ramp (1988), que inclui dados da anatomia do gineceu de Erythrochiton brasiliensis Nees \& Mart., o de Beltrati (1991), sobre semente e plântula de Esenbeckia febrifuga (A. St.-Hil.) A. Juss. ex Mart., e os artigos de Souza et al. $(2003,2004)$ sobre a anatomia floral de Pilocarpus pennatifolius Lem. e de Metrodorea nigra A. St.-Hil., respectivamente. Porém, esses e outros poucos estudos morfoanatômicos existentes sobre os gêneros neotropicais da família ainda não permitem uma codificação adequada de caracteres para análises cladísticas e limitam fortemente a formulação de hipóteses robustas sobre a evolução no grupo.

Entre os tipos florais mais instigantes na família, estão as flores tubulosas, conhecidas em diversos gêneros da subfamília Rutoideae, como Correa (único gênero da subtribo Correinae, tribo Boronieae) e na maioria dos gêneros da subtribo Galipeinae, tribo Galipeeae - nomes propostos em Kallunki \& Pirani (1998) em substituição aos nomes ilegítimos Cuspariinae e Cusparieae do sistema de classificação de Engler (1931). As flores tubulosas nesses táxons têm formatos e simetrias variadas, que certamente têm relação com os sistemas de polinização e com a evolução dos diversos gêneros e espécies do grupo.

A flor tubulosa da espécie australiana Correa speciosa Donn ex Andrews (tribo Boronieae, Rutoideae), embora aparentemente gamopétala, foi reportada por Troll (1937) e posteriormente com maior detalhe por Hartl (1957) como um caso de falsa simpetalia. A mera análise morfológica dessa flor mostra efetivamente que as pétalas são livres na base, e cortes anatômicos transversais através da região tubular da corola revelam que na sutura entre pétalas adjacentes persistem duas camadas de epiderme e ainda uma camada de cutícula entre elas, o que não caracteriza uma conação verdadeira (Hartl 1957, Weberling 1989). Nos vários gêneros de Galipeinae, grupo exclusivamente neotropical, são descritas diversas formas e extensões de união entre partes das flores, notadamente corolas simpétalas ou aparentemente simpétalas (seja parcialmente ou em longa extensão), filetes mais ou menos unidos entre si e com o tubo da corola e carpelos com variados graus de união entre si (e.g. Engler 1874, 1931, Kallunki 1992, 1998, Kallunki \& Pirani 1998, Pirani 1999, 2002, 2004, Pirani \& Kallunki 2007). Estes dois últimos autores têm utilizado os termos conação e adnação na acepção usual, i.e. referindo-se à união entre peças de um mesmo ciclo ou entre peças de ciclos diferentes. Por outro lado, empregam os termos “coerentes” e "aderentes” para a condição de pétalas ou filetes unidos apenas por forte entrelaçamento de tricomas, seja entre peças de um mesmo ciclo (coerentes), seja entre os dois ciclos citados (aderentes). Também o fato de Galipea Aubl. e alguns outros gêneros de Galipeinae apresentarem duas anteras férteis e cinco (ou mais) estaminódios é intrigante, devido à condição básica na subtribo ser a isostemonia. No entanto, faltam estudos morfoanatômicos detalhados que demonstrem claramente a natureza ou condição desses atributos todos, sem dúvida relevantes na evolução dos gêneros e espécies e em uso corrente na taxonomia da subtribo. Considere-se ainda a necessidade de detecção clara de homologias e de codificação adequada desses caracteres na implementação das análises cladísticas, paradigmáticas na Sistemática moderna.

Assim, o presente trabalho tem por objetivo a investigação da morfologia e anatomia da flor de espécies de Galipea, gênero neotropical florestal, com cerca de treze espécies sulamericanas e duas na América Central (Pirani \& Kallunki 2007). Foi dada ênfase na expressão de conação/coerência ou adnação/ aderência das peças florais e na elucidação da natureza dos estaminódios. Como existem poucos estudos sobre anatomia de órgãos reprodutivos na família (Sousa et al. 2005), objetiva-se também com esse estudo contribuir para o conhecimento sobre a estrutura anatômica das flores em Galipeinae. Dados mais precisos sobre a anatomia floral de representantes desse grupo, junto com outros caracteres já bem estabelecidos, permitirão uma reavaliação de sua importância na sistemática de Galipeinae, uma verificação de sua evolução sobre a filogenia disponível para o grupo (Groppo et al. 2008), e poderão auxiliar no esclarecimento de algumas das relações evolutivas intra-familiares de Rutaceae.

\section{Material e métodos}

Exemplares floridos de cinco espécies de Galipea foram obtidos de populações naturais encontradas em florestas da Bahia (Galipea laxiflora Engl.), do Espírito Santo (Galipea carinata Pirani), de Minas Gerais (Galipea ciliata Taub. e Galipea jasminiflora (A. St.-Hil.) Engl.) e da Costa Rica (Galipea dasysperma Gómez-Laur. \& Q. Jiménez). Parte do material foi usada na preparação de exsicatas e flores em diversos estádios de desenvolvimento foram fixadas em FAA em etanol 50\% (Johansen 1940) para estudo anatômico. Lâminas permanentes foram preparadas com botões jovens e em pré-antese, previamente desidratados em série butanólica terciária, emblocados em parafina e seccionados transversalmente ao micrótomo rotativo, segundo técnica descrita por Johansen (1940 apud Kraus \& Arduin 1997). 
A coloração dos cortes seriados foi feita com azul de Astra 1\% e safranina 1\% em etanol 50\% (Bukatsch 1972 apud Kraus \& Arduin 1997). A montagem das lâminas histológicas foi feita com Bálsamo do Canadá. Diagramas da morfologia das flores como vista nos cortes anatômicos analisados, mostrando apenas os contornos das peças e sua vascularização, como os constantes em Eames (1961), Leinfellner (1964) e Weberling (1989), foram elaborados com o auxílio de câmara clara acoplada a estereomicroscópio e fotografias foram tomadas com câmera digital Leica modelo DFC 320, acoplada a microscópico óptico Leica DMLB.

A terminologia de morfologia floral adotada segue as definições de Weberling (1989).

Material estudado: Galipea carinata Pirani - BRASIL. EsPíRITO SANTO: Guarapari, Rodovia do Sol, estrada que liga a BR 101 à Praia do Sol e Praia Setiba na ES-060, a 4 km da BR 101, 40²7' W, 20³1' S, 23-II-1988, J.R. Pirani et al. 2414 (NY, SPF).

Galipea ciliata Engl. - BRASIL. MinAs Gerais: Mato Verde, estrada para São João do Bonito, 12,5 km da Rodovia Mato Verde-Monte Azul (BR-122), 15¹8'21” S 4249’37” W, 7-IV-2004, J.R. Pirani et al. 5464 (K, MBM, NY, SPF).

Galipea dasysperma Gómez-Laur. \& Q. Jiménez - COSTA RICA. Guanacaste: S of Santa Cecília, $4 \mathrm{~km} \mathrm{~N}$ of La Fitilla Station, ca. $11^{\circ} 02^{\prime}$ N, 85²6’ W, 300 m, 15-VI-1989, J.A. Kallunki et al. 298 (CR, MO, NY, SPF); Limon: Talamanca, Suretka, 9³5’20” N, 8253’50” W, 200 m, 19-VII-1995 (fl), A. Cascante et al. 554 (CR, F, K, MO).

Galipea jasminiflora (A. St.-Hil.) Engl. - BRASIL. EsPíRITO SANTO: Santa Teresa, São Sebastião, Várzea Alegre, 1,4 km de Santa Bárbara na estrada para Colatina, Fazenda do Sr. Djalma Novelli, 1950’48” \$ 4043'10” W, ca. $180 \mathrm{~m}$ alt., 30-I-2002, J.R. Pirani et al. 4923 (K, MBM, NY, RB, SPF); Minas GeraIs: Cristália, Fazenda Cabral, 16³4’00” S 42॰47'26” W, margem direita do Rio Itacambiruçu, 500 m, 31-III-2004, J.R. Pirani et al. 5367 (FUEL, K, MBM, NY, $\mathrm{RB}, \mathrm{SPF})$.

Galipea laxiflora Engl. - BRASIL. BAHIA: Ilhéus, 3 km north of Rodoviaria, Mata da Esperança, 1446'55” \$ 3904'09” W, 50 m, 16-III-1996, W.W. Thomas et al. 11064 (CEPEC, NY, SPF).

\section{Resultados}

Morfologia geral da flor (figuras 1-17) - As flores das cinco espécies são pentâmeras (ocasionalmente hexâmeras em G. carinata), diclamídeas, bissexuadas, reunidas em inflorescências terminais eretas do tipo tirsóide (Weberling 1989). O cálice é gamossépalo, tubuloso ou urceolado, com lobos curtos correspondentes ao ápice das sépalas, de coloração creme-esverdeada, inteiramente glabro ou com tricomas simples na face abaxial. A corola, alva a creme, tem porção tubulosa longa e estreita, com cinco lobos de prefloração coclear-descendente, expandidos no ápice. Estes são ligeiramente desiguais e sua disposição na antese conferem simetria levemente bilabiada e zigomorfa à flor, visto que um (ou raro dois) deles fica(m) em posição vertical - o lobo mais interno -, enquanto os demais tomam posição horizontal, em ângulo reto como o tubo corolino, formando uma plataforma em que pousam os insetos visitantes da flor. Ambas as faces da corola são revestidas por espesso indumento de tricomas simples, adpressos, que são retos na metade proximal da corola, mas retorcidos na parte distal e em grande parte entrelaçados, fato que vai conferir a manutenção das pétalas em estreito contato entre si (figuras 1, 10, 16) e com os filetes (figura 17). Aqui temos um dos fatores responsáveis pelo aspecto tubular da flor, que portanto não é genuinamente gamopétala, pois trata-se de coerência por entrelaçamento de tricomas. Isso será melhor detalhado no tópico sobre anatomia (figura 72).

O androceu é constituído por cinco estames (ocasionalmente seis em $G$. carinata) cujos filetes são conatos em tubo na metade proximal e parcialmente adnatos à corola da base à porção mediana (figuras 2 , 17). A face adaxial dos filetes é densamente revestida por indumento adpresso, seríceo, com longos tricomas reflexos. Na sua porção distal, o tubo de filetes sustenta duas anteras e cinco estruturas tradicionalmente denominadas estaminódios (ocasionalmente seis em G. carinata). Estas são longas, lineares e pilosas, três delas alternadas às pétalas, duas opostas a elas, todas exsertas do tubo da corola na antese (figuras 8, 10, 12, 14). As duas anteras são tetrasporangiadas, flanqueando a pétala mais interna (abaxial), extrorsas na antese, glabras, dotadas na base de uma expansão geralmente cuculada denominada apêndice. O apêndice de uma antera é conato ao da outra, enquanto as tecas são apenas coerentes uma à outra, embora firmemente adpressas, em toda extensão dos flancos ou parcialmente (figuras $3,8,14,15)$. As duas únicas exceções no gênero, quanto a esse aspecto, são $G$. dasysperma, em que os apêndices basais são praticamente indistintos e as anteras quase totalmente livres (figura 11), e G. panamensis T. S. Elias, não analisada em detalhe no presente estudo mas que, também, exibe anteras livres e sem apêndices. Na antese, as duas anteras das flores de Galipea se dispõem eretas, flanqueando a pétala mais interna e que permanece em posição vertical (figuras 12,17), enquanto as demais pétalas e os estaminódios assumem posição horizontal, geralmente formando um ângulo reto com o tubo da corola. As anteras caem facilmente da flor, como peça 


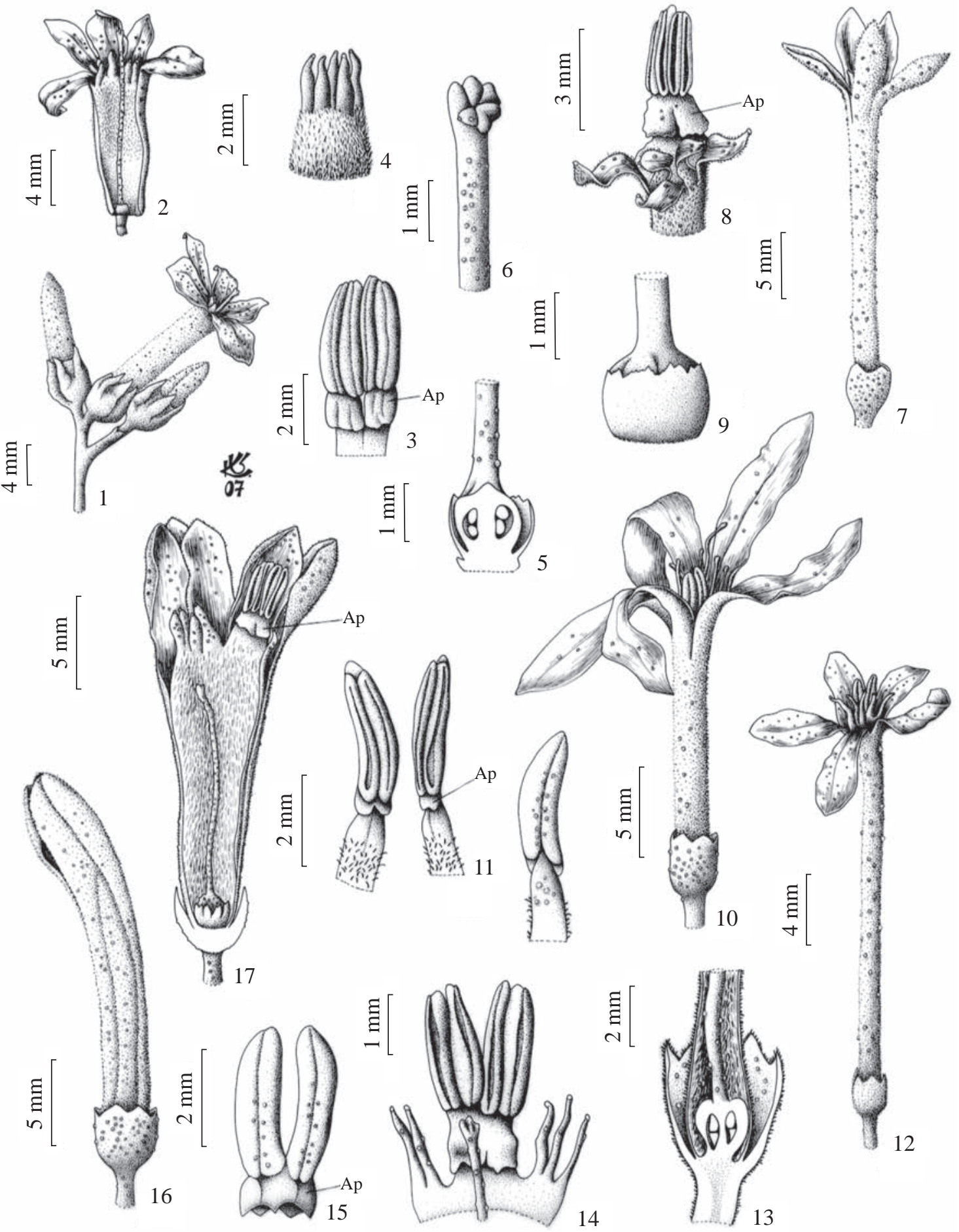

Figuras 1-17. Morfologia externa de Galipea. 1-6. G. carinata. 1. Trecho da inflorescência. 2. Flor com a corola aberta e rebatida. 3. Parte distal de dois estames, vista adaxial. 4. Parte distal de grupo de estaminódios. 5. Parte basal do gineceu, ovário e disco em corte longitudinal. 6. Parte distal do estilete. 7-9. G. ciliata. 7. Flor. 8. Parte distal do androceu, com duas anteras e cinco estaminódios. 9. Base do gineceu envolvida pelo disco. 10-11. G. dasysperma. 10. Flor. 11. Estames, vistas adaxial e abaxial (direita). 12-15. G. jasminiflora. 12. Flor na antese. 13. Base da flor em corte longitudinal, expondo tubo floral, disco e ovário. 14. Parte distal do androceu, aberta rebatida, com duas anteras e cinco estaminódios; à frente o estilete. 15. Anteras conatas na base. 16-17. G. laxiflora. 16. Botão floral. 17. Flor em corte longitudinal, expondo tubo floral com denso indumento, duas anteras flanqueando a pétala mais interna, quatro estaminódios e gineceu envolvido na base pelo disco. (Ap = apêndice basal da antera). 
única, porém os estaminódios persistem até a caducidade da corola, que vai ressecando no início da formação do fruto.

O gineceu é pentacarpelar (ocasionalmente hexacarpelar em G. carinata), sincárpico, com ovário súpero pentalobado, estilete alongado, cilíndrico, e estigma capitado, pentalobado (figuras $5,6,17$ ). O estilete fica incluso no tubo da flor durante a fase inicial da antese, alongando-se bastante depois que as anteras caem, até ficar exserto, em consonância com a ocorrência de protandria. Os óvulos (rudimentos seminais) são dois por lóculo, anátropos, bitegumentados, crassinucelados, inseridos marginalmente no carpelo, superpostos. Um disco cupuliforme e delgado circunda o ovário, sendo provavelmente nectarífero (figuras 5, 9, 17).

Todos os verticilos da flor são dotados de glândulas (cavidades revestidas por células epiteliais secretoras) de dimensões variadas, na maioria bem proeminentes e evidentes mesmo a olho nu. Ficam associadas aos tecidos parenquimáticos, principalmente subepidérmicos (figuras 19, 31, 49, 68, 74, 83), sendo maiores e mais numerosas em certas regiões, por exemplo no ápice do ovário e face externa das pétalas e sépalas.

Vascularização, disposição e graus de união das peças florais (figuras 18-86) - No pedicelo das flores das espécies estudadas, já ao nível da emergência de bractéolas, o sistema vascular (estelo) apresenta-se formado por um cilindro central composto por vários (cerca de 14-18) feixes fundamentais, que circundam uma medula parenquimática (figuras 18,19 ). No receptáculo floral há divergências de tecidos vasculares, formando os traços dos elementos do perianto, androceu, disco e gineceu. Inicialmente, cinco (ocasionalmente seis em G. carinata) feixes dirigem-se para a periferia do receptáculo e dão origem a divergências para as peças florais, de modo que se formam primeiro dois, depois três e quatro círculos concêntricos de tecidos condutores, o mais interno com cerca de 16 a 18 feixes (figuras 20-22). Nos cortes longitudinais ilustrados (figuras 30,31 ) pode-se ver que esses círculos concêntricos de feixes correspondem à vascularização dos verticilos florais, sendo que os traços que suprem o cálice, a corola, o androceu e o gineceu emergem do eixo independentemente, sucessivamente.

Na região correspondente à base do ovário (figura 22), observa-se o círculo de traços do cálice, mais periférico, logo iniciando-se também a separação entre os tecidos desse ciclo de sépalas e os tecidos que continuam constituindo o receptáculo floral. Os feixes calicinais são 15 (ou 18 nas raras flores hexâmeras de G. carinata), correspondendo a um feixe dorsal de sépala e dois laterais irrigando cada sépala. Internamente ao círculo de feixes do cálice, observam-se: um círculo de cinco (raramente seis) traços que irão vascularizar as pétalas e internamente a este um círculo de feixes que constituem os traços do androceu; na sequência aparece um círculo que irrigará o disco e, em seguida, inicia-se a separação dos tecidos constituintes da parte basal do ovário, onde se diferenciam os dois círculos concêntricos de feixes do gineceu (figura 23): o mais externo correspondente aos feixes dorsais de carpelo, que divergiram dos complexos estamino-carpelares, em frente aos traços de sépalas; internamente situam-se os feixes ventrais de carpelo.

Num nível pouco mais acima, já se observa a completa individualização estrutural do cálice, separando-se de um bloco receptacular central, e tem início também a separação da base do ovário, com os traços das pétalas, dos estames e do disco distanciando-se progressivamente do centro do eixo (figuras 23, 24). Começa em seguida a individualização estrutural do disco, como um círculo composto de numerosos feixes muito aproximados entre si (figuras 24, 25, 49, 81), restando um anel de corola e androceu adnatos, constituindo este anel o tubo floral (figuras 23-25, 30-36, 49-54, 68). Esse tubo floral, definido aqui como resultado da adnação da base das pétalas com os filetes, apresenta, nos seus níveis inferiores, um círculo de cinco traços petalares externos e maiores e um círculo de cinco traços estaminais, mais internos, menores e alternados aos das pétalas (figura 68). Nas raras flores hexâmeras de

Figures 1-17. External morphology of Galipea. 1-6. G. carinata. 1. Part of an inflorescence. 2. Flower with the corolla opened. 3. Distal portion of two stamens, adaxial view. 4. Distal portion of a group of staminodes. 5. Basal portion of gynoecium, ovary and disc, longsection. 6. Distal portion of style. 7-9. G. ciliata. 7. Flower. 8. Distal portion of androecium, with two anthers and five staminodes. 9. Base of gynoecium surrounded by a disc. 10-11. G. dasysperma. 10. Flower. 11. Stamens, adaxial and abaxial views (right). 12-15. G. jasminiflora. 12. Flower at anthesis. 13. Base of flower in longisection, exposing the floral tube, disc and ovary. 14. Distal portion of androecium, opened, with two anthers and five staminodes; the style is in front. 15. Anthers connate at base. 16-17. G. laxiflora. 16. Floral bud. 17. Flower in longisection, note dense indumentum on the floral tube, two anthers flanking the innermost petal, four staminodes and gynoecium surrounded by the disc at base. (Ap = basal appendix of anther). 


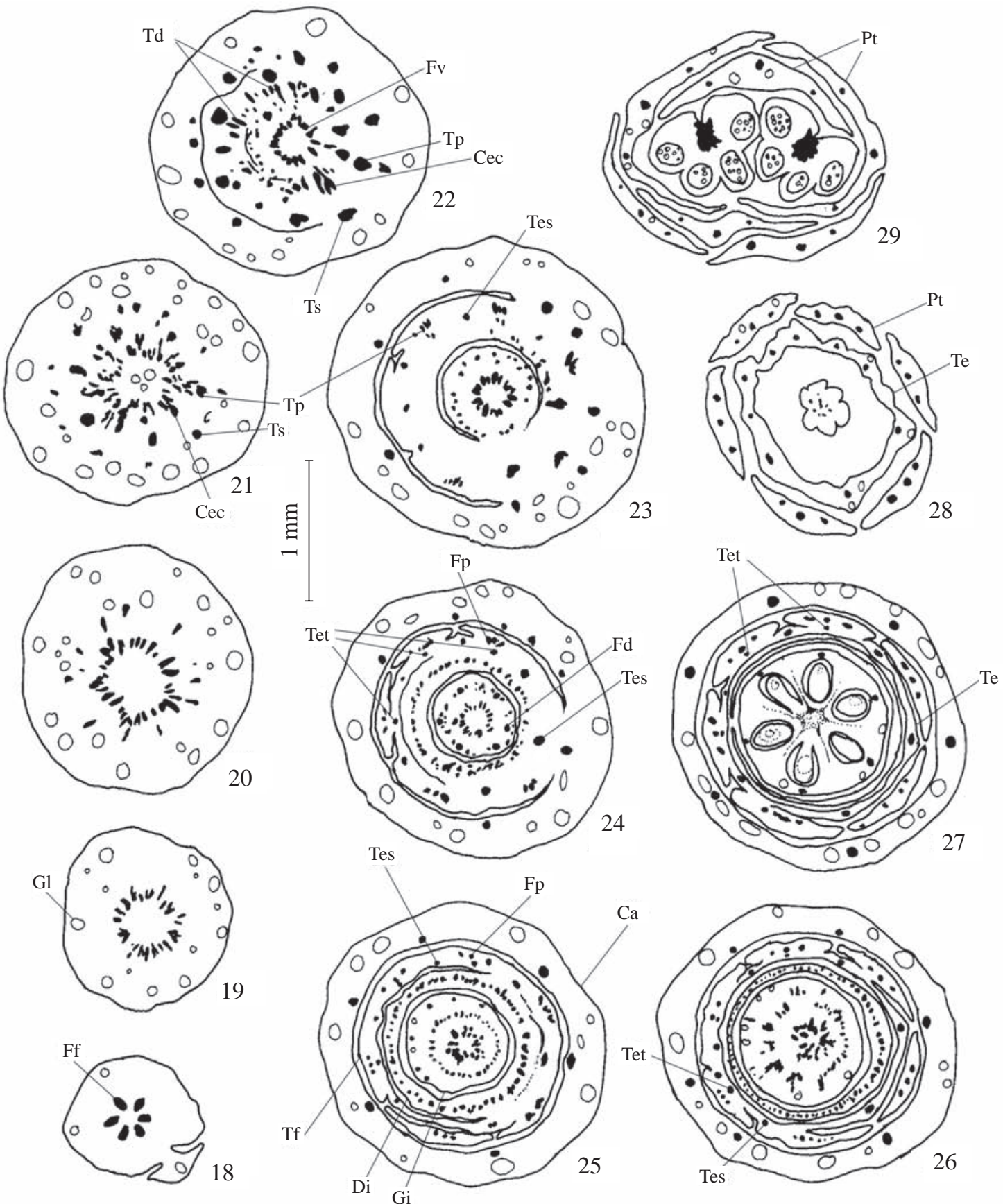

Figuras 18-29. Diagramas de seç̧ões transversais de botão floral de Galipea carinata. 18. Pedicelo. 19-22. Receptáculo em níveis sucessivos. 23-26. Região da base do ovário e do disco em níveis sucessivos. 27. Região mediana do ovário. 28. Região mediana do estilete. 29. Região das anteras. ( $\mathrm{Ca}=$ cálice; $\mathrm{Cec}=$ complexo estamino-carpelar; $\mathrm{Di}=$ disco nectarífero; $\mathrm{Fd}=$ feixe dorsal de carpelo; $\mathrm{Ff}$ = feixe fundamental; $\mathrm{Fp}$ = feixe de pétala; $\mathrm{Fs}$ = feixe dorsal de sépala; Fv = feixe ventral de carpelo; Gi = gineceu; $\mathrm{Gl}$ = glândula; $\mathrm{Pt}$ = pétala; $\mathrm{Td}$ = traço de disco; $\mathrm{Te}$ = tubo estaminal; Tes = traço de estame sepalar; Tet = traço de estaminódio; $\mathrm{Tf}$ = tubo floral; $\mathrm{Tp}$ = traço de pétala; Ts = traço de sépala).

Figures 18-29. Diagrams of transections through floral bud of Galipea carinata. 18. Pedicel. 19-22. Receptacle - successive levels. 23-26. Basal region of ovary and disc - successive levels. 27. Median region of ovary. 28. Median region of style. 29. Region of anthers. $(\mathrm{Ca}=$ calyx; $\mathrm{Cec}=$ staminal-carpelary complex; $\mathrm{Di}=$ nectariferous disc; $\mathrm{Fd}=$ dorsal bundle of carpel; Ff = fundamental bundle; $\mathrm{Fp}$ = petal bundle; $\mathrm{Fs}$ = dorsal bundle of sepal; $\mathrm{Fv}$ = ventral bundle of carpel; $\mathrm{Gi}$ = gynoecium; $\mathrm{Gl}=$ gland; $\mathrm{Pt}=$ petal; $\mathrm{Td}=$ disc trace; $\mathrm{Te}=$ staminal tube; $\mathrm{Tes}=$ trace of sepalar stamen; Tet = staminoidal trace; $\mathrm{Tf}=$ floral tube; $\mathrm{Tp}=$ petal trace; Ts = sepal trace). 
G. carinata, observam-se nesse nível seis traços petalares e seis estaminais. Portanto, o tubo floral exibe adnação dos tecidos das pétalas e estames, exceto os traços, que persistem livres, bem distintos.

Após a liberação dos traços desses verticilos mais periféricos, o tecido estelar remanescente continua organizado num sifonostelo dissecado antes de originar os traços carpelares (figuras 22, 23), que depois se separam em cerca de 30 a 36 feixes (figuras 24, 25). A vascularização do ovário será analisada em detalhe mais à frente.

Desse nível para cima, observa-se que os feixes estaminais seguirão sem qualquer ramificação, dispostos num círculo de cinco (ocasionalmente seis em $G$. carinata). Já os traços petalares, dispostos alternadamente em círculo mais externo ao do androceu, experimentam divisões e cada um deles se divide em três traços alinhados paralelamente (o do meio constituirá o feixe dorsal de pétala). Na pétala externa e na sua adjacente que será frontal à pétala interna, antes mesmo de ocorrer essa formação de três feixes paralelos, já diverge um traço em posição concêntrica adaxial, e como resultado aparecem dois novos traços que ficam alinhados ao círculo de traços estaminais (figuras 24, 32-36). Em G. dasysperma, a produção de um traço oposto a uma pétala ocorre também numa pétala adjacente à pétala interna, de modo que existirão na flor três feixes adaxialmente opostos às pétalas (figuras 55-61). A consequência disso será explorada mais à frente.

Na face externa (abaxial) do tubo floral delineiam-se invaginações e sulcos que vão aprofundando para o centro e levarão à individualização das pétalas (figuras 23, 24, 33-36, 52-55, 69, 71), cada uma delas com seus três feixes libero-lenhosos: um mediano maior (dorsal de pétala) flanqueado por dois laterais de menor calibre, dispostos muito próximos (figuras 69, 70). Em círculo mais interno a este, dispõem-se alternadamente os cinco (ocasionalmente seis em $G$. carinata) traços estaminais e dois traços opostos às pétalas (ocasionalmente 3 em G. carinata e G. dasysperma), correspondentes aos estaminódios epipétalos (e.g. figuras 24, 25, 32-36, 68).

Em Galipea carinata, o tubo floral já exibe em sua face externa (abaxial) o contorno das pétalas delineado na altura em que sua parte central ainda persiste adnata parcialmente ao disco, por uma curta extensão (figuras $23,24)$; nas demais espécies, as invaginações e sulcos no tubo floral que levam à formação das pétalas só aparecem após a sua separação total do disco, ou até em pontos acima deste na flor (figuras 32, 52, 68). Em todas as espécies, observa-se que o processo de delineamento da face abaxial das pétalas avança bem mais depressa do que o das suas faces adaxiais, que persistem ainda adnatas aos filetes no tubo floral (figuras 26, 27, 36, 53-56, 68).

No processo de individualização gradual das pétalas, que culmina com sua liberação total dos filetes, a pétala interna é a que permanece adnata aos filetes em maior extensão (figuras 37, 38), exceto em G. dasysperma, onde essa é a primeira pétala a se individualizar inteiramente (figuras 56, 57). Na antese, será essa pétala interna do padrão de prefloração coclear dessas plantas a que ficará flanqueada pelas duas anteras (figuras 29, 41, 42, 59-61, 77).

À medida que as pétalas se tornam livres, percebe-se por curta extensão a manutenção de um tubo de filetes unidos (tubo estaminal, figuras 27, 28, 37), que logo experimenta suas próprias fragmentações para originar os estaminódios e anteras (figuras 38-42, 74-76). Porém, deve-se lembrar que esse tubo recebeu adicionalmente dois traços (ou três em G. carinata) a partir de divergências de feixes petalares (figuras 23, 24, 35, 36, 57-60).

Os sulcos limitantes das superfícies externas e internas dos segmentos da corola e do androceu são revestidas por denso indumento de tricomas multicelulares unisseriados, cujo entrelaçamento confere aderência entre essas peças, resultando no aspecto tubuloso da flor. Assim, mesmo no nível em que pétalas e filetes já estão bem individualizados, observam-se as pétalas fortemente coerentes umas às outras pelos tricomas entrelaçados, os filetes coerentes uns aos outros da mesma maneira, e as pétalas e filetes aderentes entre si (figura 72).

Em quatro das espécies estudadas ( $G$. carinata, G. ciliata, G. laxiflora e G. jasminiflora), observa-se que no mesmo nível da individualização das pétalas, ou pouco acima dele, diversos sulcos vão gradualmente delineando os cinco filetes, cada um com apenas um único feixe vascular (figuras 38-42, 56-62). Os dois estames flanqueando a pétala mais interna serão funcionais e formarão anteras. Os dois estames laterais (que flanqueiam as duas anteras) e o quinto estame (frontal à pétala mais interna), alternipétalos, não formarão anteras e constituirão estaminódios - homólogos a estames inteiramente esterilizados. As duas (ou raro três em G. carinata) outras estruturas lineares da flor usualmente tratadas como estaminódios dispõem-se opostas a pétalas e são vascularizadas com traços advindos de pétalas. Portanto, é difícil interpretar a natureza desses dois estaminódios (ou apêndices petalares) epipétalos, pois surgem como expansões adaxiais das pétalas e no aspecto externo são idênticos aos estaminódios verdadeiros 

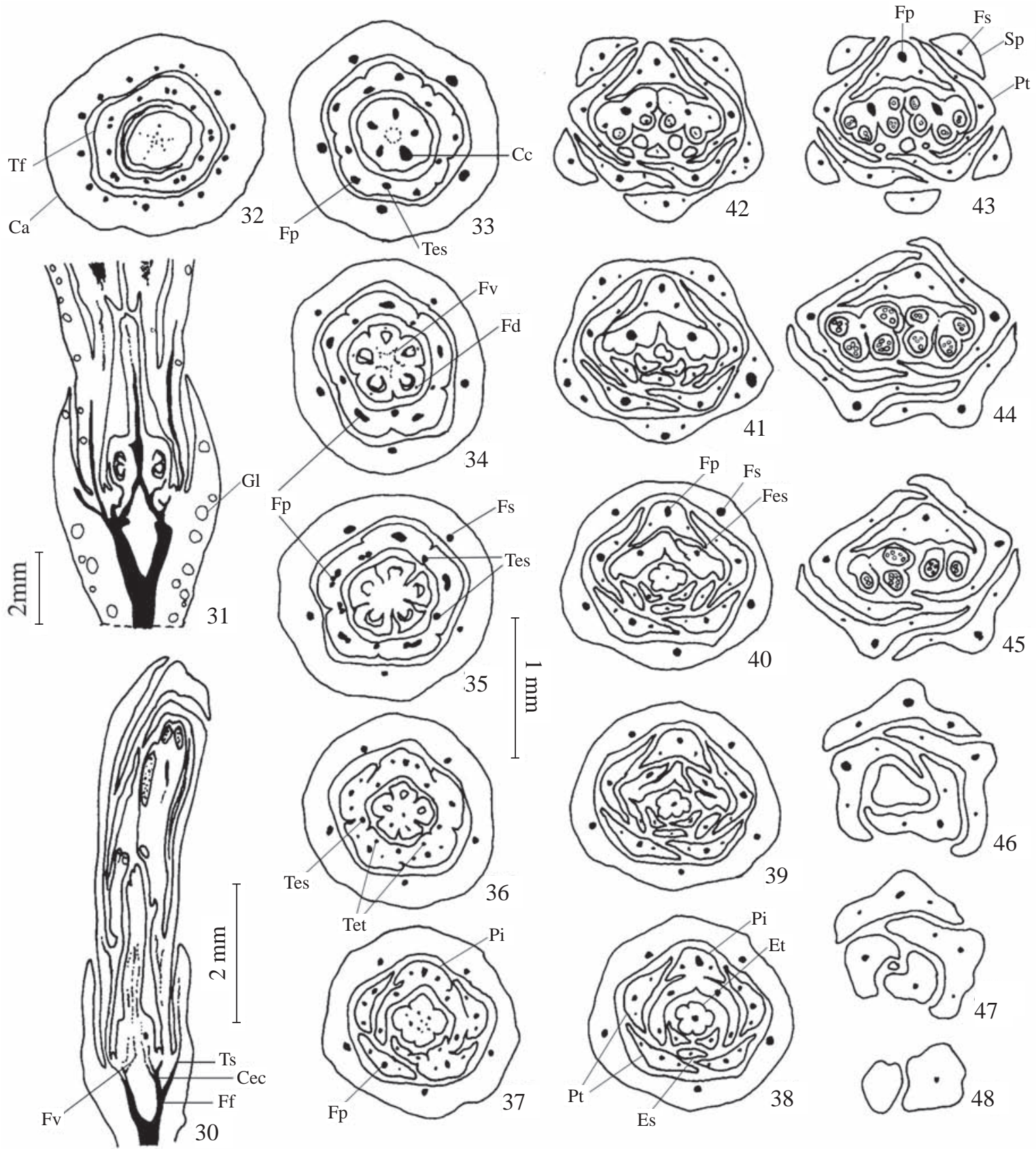

Figuras 30-48. Diagramas de seç̧ões de botão floral de Galipea jasminiflora. 30, 31. Secção longitudinal. 32-48. Seç̧ões transversais em níveis sucessivos. 32-33. Região da base do ovário. 34. Região mediana do ovário. 35-37. Região do ápice do ovário. 38. Região da base do estilete e emergência dos estaminódios. 39-45. Região das anteras. 46-48. Região distal do botão $(\mathrm{Ca}$ = cálice; $\mathrm{Cc}$ = complexo carpelar; $\mathrm{Cec}=$ complexo estamino-carpelar; Es = estaminódio; $\mathrm{Et}$ = estilete; Fd = feixe dorsal de carpelo; Fes = feixe de estame; $\mathrm{Ff}$ = feixe fundamental; $\mathrm{Fp}$ = feixe de pétala; $\mathrm{Fs}$ = feixe dorsal de sépala; $\mathrm{Fv}$ = feixe ventral de carpelo; $\mathrm{Gl}$ = glândula; $\mathrm{Pi}$ = pétala mais interna; $\mathrm{Pt}$ = pétala; $\mathrm{Sp}$ = sépal; Tes = traço de estame sepalar; Tet = traço de estaminódio; $\mathrm{Tf}$ = tubo floral; Ts = traço de sépala).

Figures 30-48. Diagrams of sections through floral bud of Galipea jasminiflora. 30, 31. Longisection. 32-48. Transections - successive levels. 32-33. Basal region of ovary. 34. Median region of ovary. 35-37. Apical region of ovary. 38. Basal region of style and rising of staminodes. 39-45. Region of the anthers. 46-48. Distal region of bud. (Ca = calyx; Cc = carpelar complex; $\mathrm{Cec}$ = staminal-carpelary complex; Es = staminode; $\mathrm{Et}=$ style; $\mathrm{Fd}$ = dorsal bundle of carpel; Fes = staminal bundle; $\mathrm{Ff}=$ fundamental bundle; $\mathrm{Fp}$ = petal bundle; $\mathrm{Fs}$ = dorsal bundle of sepal; $\mathrm{Fv}$ = ventral bundle of carpel; $\mathrm{Gl}$ = gland; $\mathrm{Pi}$ = innermost petal; $\mathrm{Pt}$ = petal; $\mathrm{Sp}$ = sepal; Tes = trace of sepalar stamen; Tet = staminoidal trace; $\mathrm{Tf}$ = floral tube; $\mathrm{Ts}$ = sepal trace). 

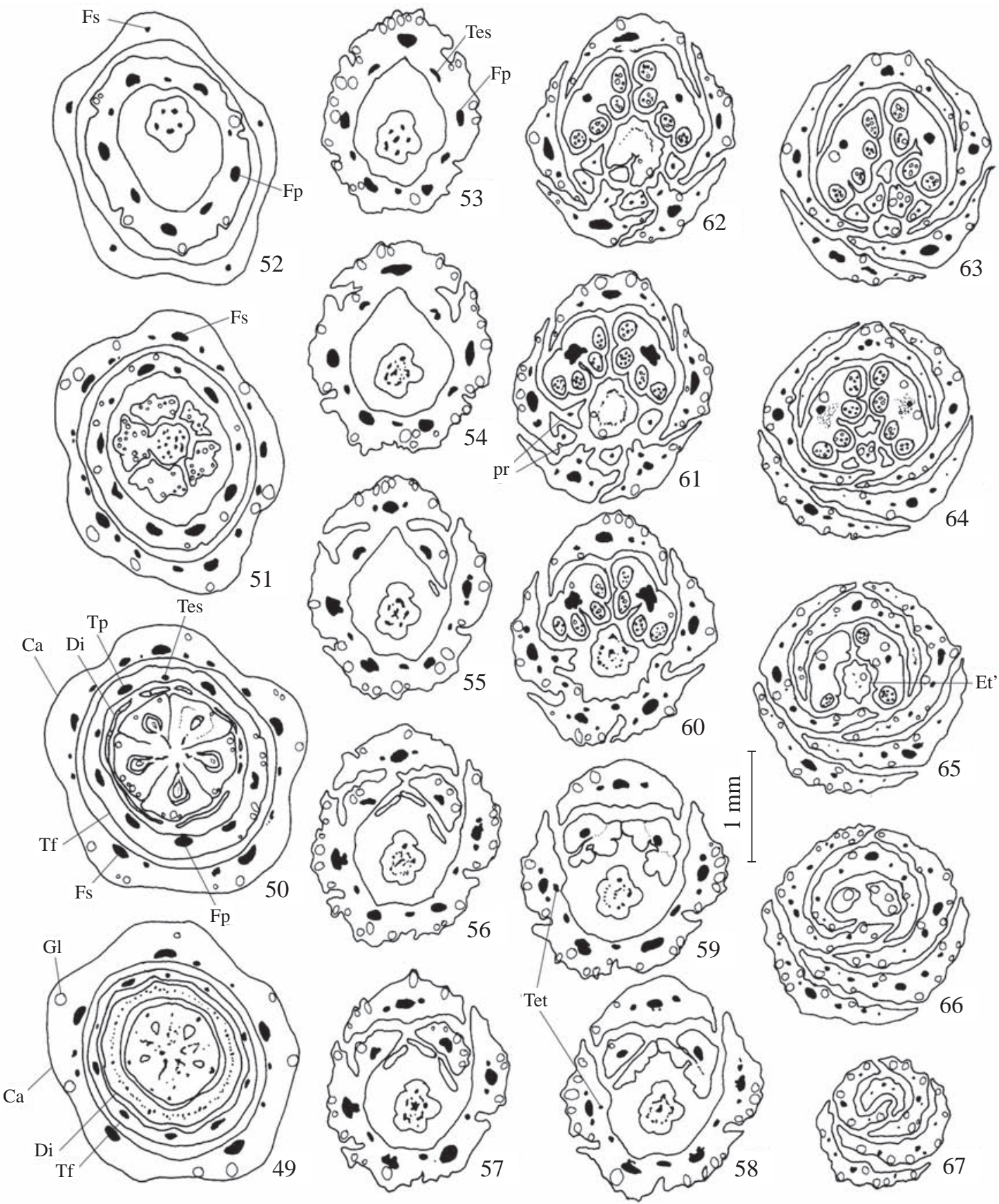

Figuras 49-67. Diagramas de secções transversais em níveis sucessivos de botão floral de Galipea dasysperma. 49. Região da base do ovário. 50-51. Região do ápice do ovário. 52. Região da base do estilete. 53-55. Região da individualização das pétalas. 56-59. Região da base das anteras. 60-62. Região da emergência dos estaminódios. 63-66. Região da parte distal das anteras. 67. Região distal do botão. (Ca = cálice; $\mathrm{Di}=$ disco nectarífero; Et' = estigma; Fp = feixe de pétala; Fs = feixe dorsal de sépala; Gl = glândula; pr = protuberâncias da divergência dos estaminódios epipétalos; Tes = traço de estame sepalar; Tet = traço de estaminódio; $\mathrm{Tf}=$ tubo floral; Tp = traço de pétala).

Figures 49-67. Diagrams of transections made at successive levels of floral bud of Galipea dasysperma. 49. Basal region of ovary. 50-51. Apical region of ovary. 52. Basal region of style. 53-55. Region where the petals are formed. 56-59. Region of the base of anthers. 60-62. Region where the staminodes arise. 63-66. Region of the distal portion of anthers. 67. Distal region of bud. $(\mathrm{Ca}=$ calyx; $\mathrm{Di}=$ nectariferous disc; Et' = stigma; Fp = petal bundle; Fs = dorsal bundle of sepal; $\mathrm{Gl}=$ gland; $\mathrm{pr}=$ protuberance from the divergence of epipetalous staminodes; Tes = trace of sepalar stamen; Tet = staminoidal trace; $\mathrm{Tf}=$ floral tube; $\mathrm{Tp}=$ petal trace). 

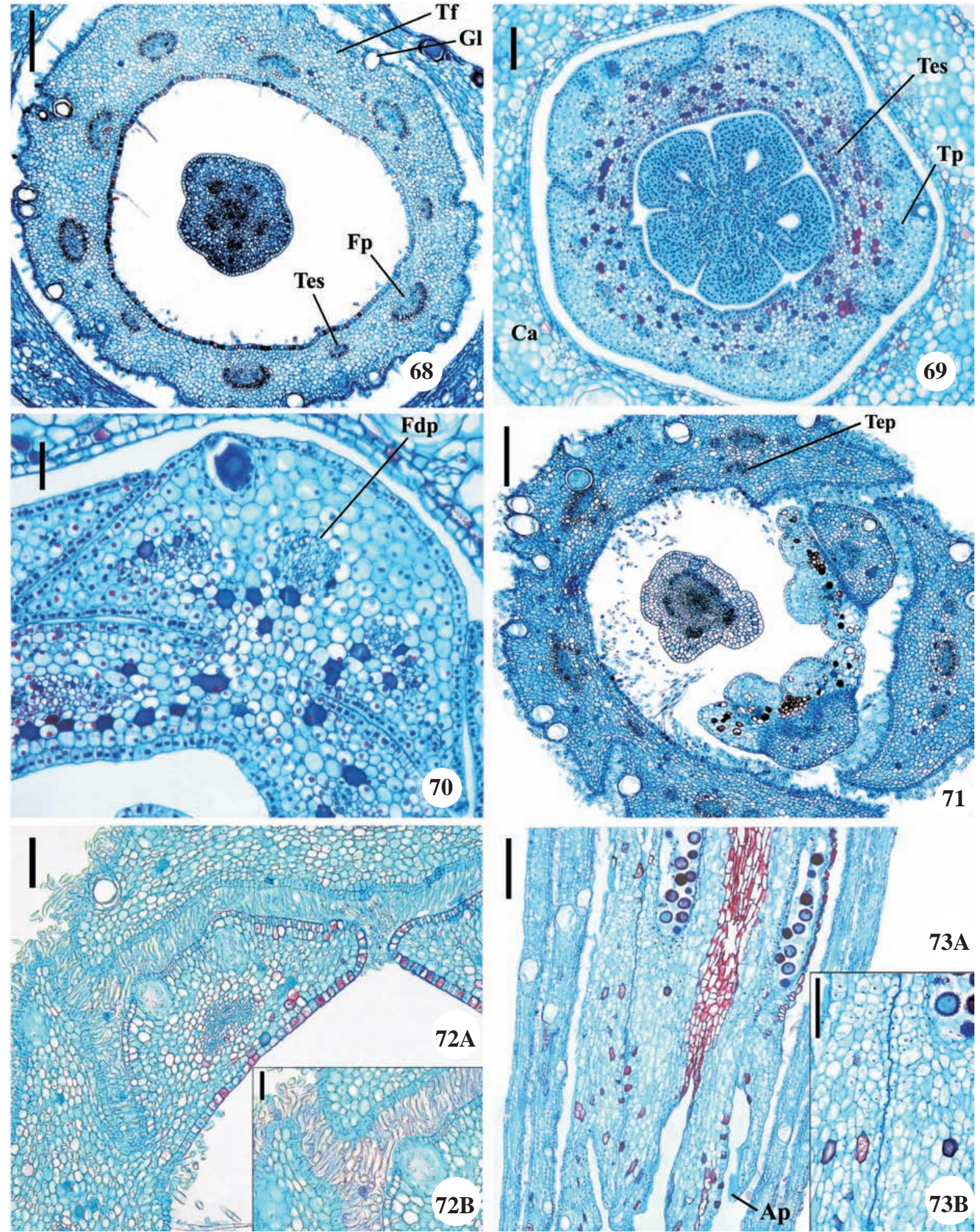

Figuras 68-73. Fotomicrografias de seç̧ões transversais (68-72) e longitudinal (73) de botão floral de Galipea. 68. Região da base do estilete, G. dasysperma. 69. Região do ápice do ovário, G. jasminiflora. 70. Detalhe da pétala mais interna conata ao tubo estaminal, G. jasminiflora. 71. Região da base das anteras, G. dasysperma. 72A e B. Detalhes do entrelaçamento de tricomas entre pétalas e filetes, G.dasysperma. 73A e B. Região da base das anteras de G. jasminiflora, com os apêndices; no detalhe as epidermes distintas de duas anteras adjacentes. (Ap = apêndice basal da antera; $\mathrm{Gl}$ = glândula; $\mathrm{Fdp}$ = feixe dorsal de pétala; $\mathrm{Fp}$ = feixe de pétala; Tep = traço de estaminódio epipétalo; Tes = traço de estame sepalar; $\mathrm{Tf}=$ tubo floral; $\mathrm{Tp}=$ traço de pétala). Barra = $500 \mu \mathrm{m}$ (68, 71,73A), $250 \mu \mathrm{m}$ (73B), $200 \mu \mathrm{m}$ (69, 72A), $100 \mu \mathrm{m}$ (70), $50 \mu \mathrm{m}$ (72B). 
(alternipétalos): finos, alongados e geralmente pilosos (figuras 8, 38-42, 74, 76).

A flor de $G$. dasysperma exibe alguns aspectos bem diferentes das demais espécies, porém nela a individualização dos estaminódios opostos às pétalas é bem mais flagrante. Os dois estames férteis são isolados do tubo floral antes mesmo que se observe qualquer indício de invaginações e sulcos na face adaxial do tubo (figuras 56-59). Estas surgirão em níveis mais distais na flor, e levarão à formação de seis estruturas lineares, onde apenas três delas correspondem a estames inteiramente esterilizados (os três alternipétalos, como nas demais espécies). Já as outras três emergem de protuberâncias muito conspícuas da superfície adaxial mediana de três pétalas (a mais externa, a adjacente a ela e a consecutiva a esta), cada uma delas sendo irrigada por um traço advindo do feixe mediano de cada uma dessas pétalas (figuras 58, 61, 71). Essa espécie contrasta com as demais também no fato de que a adnação e aderência dos estaminódios às pétalas é bem tênue: cada estaminódio pode ser facilmente destacado até a base na flor, e nas figuras 61 e 62 percebe-se a razão pela qual os estaminódios opostos a pétalas são um pouco mais resistentes a serem destacados manualmente: a conexão deles às pétalas é mantida por certa extensão por estreitas pontes medianas. Outro aspecto contrastante dessa espécie reside nos seus apêndices da base das anteras muito reduzidos e aplanados (não cuculados como é comum no gênero), com reduzida área de conação de um ao outro (figuras 58, 59). Excepcionalmente, um dos espécimes aqui examinados (A. Cascante et al. 554) apresenta flores com quatro anteras bem diferenciadas, todas ligeiramente conatas na base pelos curtos apêndices, e apenas um estaminódio alternado a pétalas e dois estaminódios opostos a pétalas.

Em todas as cinco espécies estudadas, nos dois estames flanqueando a pétala interna, o surgimento de expansões, invaginações e pregas nas faces adaxiais e laterais, em níveis sucessivos, constituirão o amplo apêndice basal, cuculado, não-vascularizado, das duas anteras (figuras 39-42, 58, 59, 73, 76). Cada estaminódio e antera são supridos por um só feixe vascular. As anteras maduras são bitecas, tetrasporangiadas (figura 29), e ficam justapostas lateralmente, apenas coerentes pelas epidermes adjacentes, claramente diferenciadas, até a região submediana (figuras $73,78,80$ ); conação foi observada somente em curta extensão (figura 79). No conectivo existe o tecido vascular na região central e, em torno desta, tecido parenquimático e tecido com células de paredes bem espessadas, lignificadas. Na parede da antera madura, logo abaixo da epiderme, encontra-se o endotécio formado de uma série de células colunares, seguido de camadas médias pouco a muito comprimidas (figura 80).

No sentido da porção distal da flor, as terminações das pétalas vão fechando o arranjo coclear num domo apical (figuras 46-48, 66, 67).

No tocante ao gineceu, os carpelos são antepétalos, peltados e congenitalmente fechados, conatos uns aos outros axial e lateralmente na maior extensão inclusive no estilete e estigma (gineceu sincárpico, figuras 27, 68, 81, 82). Apenas na porção mediana-superior do ovário (acima das placentas) observa-se evidência de união posgenital dos carpelos, pela presença de epiderme bem diferenciada nas superfícies laterais de carpelos contíguos (figuras 27, 34, 50, 82-86), e no ápice do ovário formam-se profundos sulcos (figuras 35, 36, 69, 83, 85) que fazem a separação parcial de cada um dos cinco (raramente seis) carpelos em relação aos adjacentes. Tais sulcos avançam profundamente no ovário, mas não chegam a alcançar a parte central que mantém a sincarpia. Ademais, na região da inserção dos óvulos, é possível evidenciar a sutura das margens de cada carpelo, ali fechadas apenas posgenitalmente (figuras 84, 86). Tal conformação possibilita a deiscência septicida da cápsula madura. Cabe lembrar aqui que a cápsula de Galipea sofre também deiscência loculicida, com a formação de uma fenda a partir do ápice em direção à parte ventral de cada carpelo, mas nos cortes do ovário no botão floral não se visualiza ainda qualquer evidência anatômica disso.

O ovário mostra padrão de vascularização complexo, com muitos feixes de dimensões variáveis, maiores e menores. Os traços carpelares separam-se em vários

Figures 68-73. Photomicrographs of transections (68-72) and longisection (63) of floral buds of Galipea. 68. Basal region of the base of style, G. dasysperma. 69. Apical region of ovary, G. jasminiflora. 70. Detail of the innermost petal, connate to the staminal tube, G. jasminiflora. 71. Basal region of the anthers, G. dasysperma. 72A and B. Details of close intertwining of trichomes between petals and filaments, G.dasysperma. 73A and B. Basal region of anthers of G. jasminiflora, with the appendices; in the detail the distinct epidermis of two adjacent anthers. (Ap = basal appendix of anther; $\mathrm{Gl}$ = gland; $\mathrm{Fdp}=$ dorsal bundle of petal; $\mathrm{Fp}=$ petal bundle; $\mathrm{Tep}=$ trace of epipetalous staminode; Tes = trace of sepalar stamen; $\mathrm{Tf}=$ floral tube; $\mathrm{Tp}=$ petal trace). Bar $=500 \mu \mathrm{m}$ (68, 71, 73A), $250 \mu \mathrm{m}$ (73B), $200 \mu \mathrm{m}$ (69, 72A), $100 \mu \mathrm{m}$ (70), $50 \mu \mathrm{m}$ (72B). 

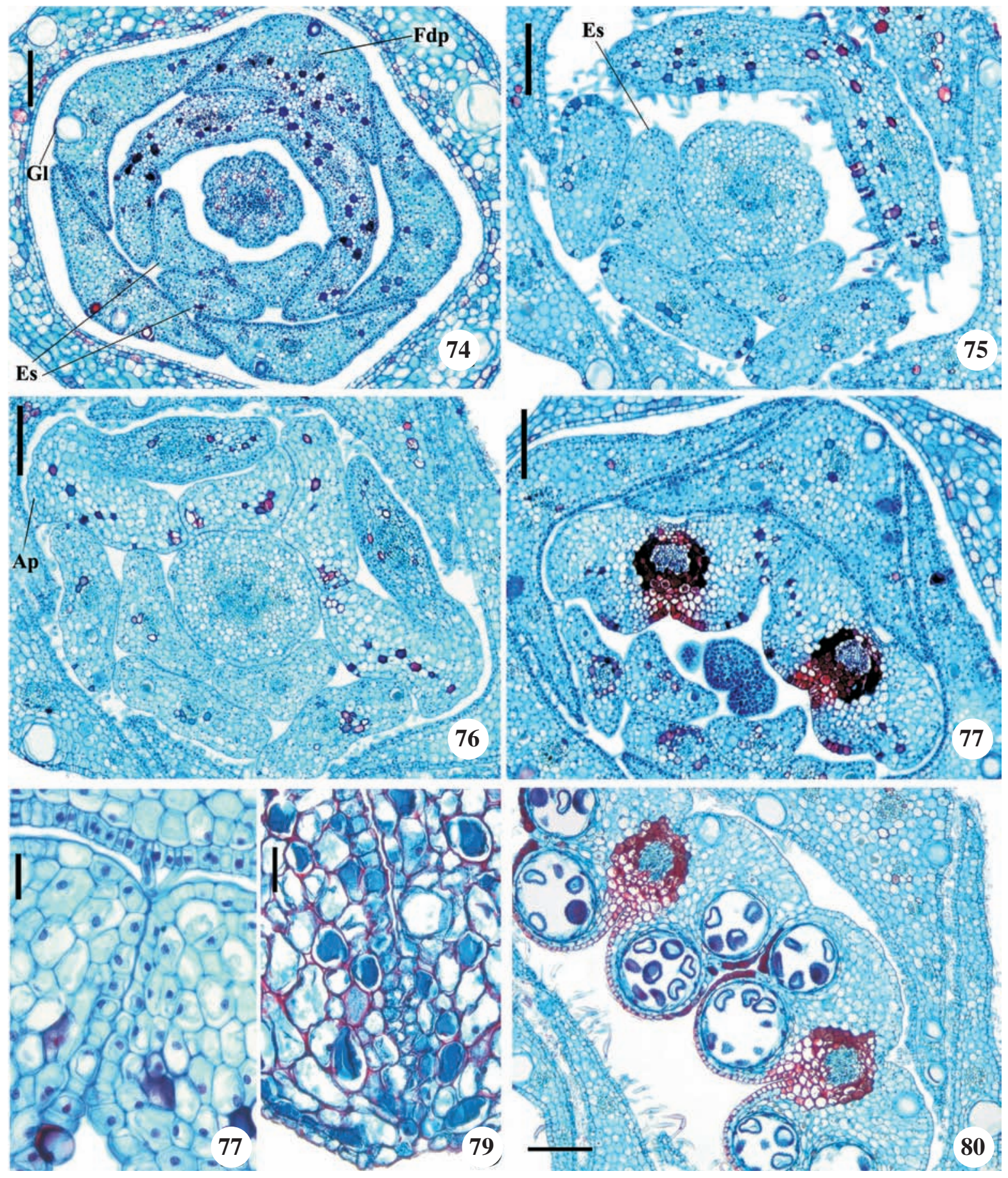

Figuras 74-80. Fotomicrografias de seç̧ões transversais de botão floral de Galipea. 74-78, 80. G. jasminiflora. 74-75. Região da individualização das pétalas e dos estaminódios (epipétalos e epissépalos). 76. Região do apêndice basal das anteras. 77, 78, 80. Região das tecas. 78. Detalhe de duas anteras adjacentes unidas. 79. G. ciliata: Detalhe de duas tecas adjacentes unidas. (Ap = apêndice basal da antera; Es = estaminódio epipétalo; $\mathrm{Fdp}=$ feixe dorsal de pétala; $\mathrm{Gl}$ = glândula). Barra = $300 \mu \mathrm{m}$ (74-77, 80), $50 \mu \mathrm{m}$ (78), $100 \mu \mathrm{m}$ (79).

Figures 74-80. Photomicrographs of transections of floral buds of Galipea. 74-78, 80. G. jasminiflora. 74-75. Region of the formation of petal and staminodes (epipetalous and episepalous). 76. Region of the basal appendices of anthers. 77, 78, 80. Region of thecae. 78. Detail of two joined adjacent anthers. 79. G. ciliata. Detail of two joined adjacent thecae. (Ap $=$ basal appendix of anther; Es = epipepalous staminode; $\mathrm{Fdp}=$ dorsal bundle of petal; Gl = gland). Bar = $300 \mu \mathrm{m}(74-77,80), 50 \mu \mathrm{m}$ (78), $100 \mu \mathrm{m}$ (79). 


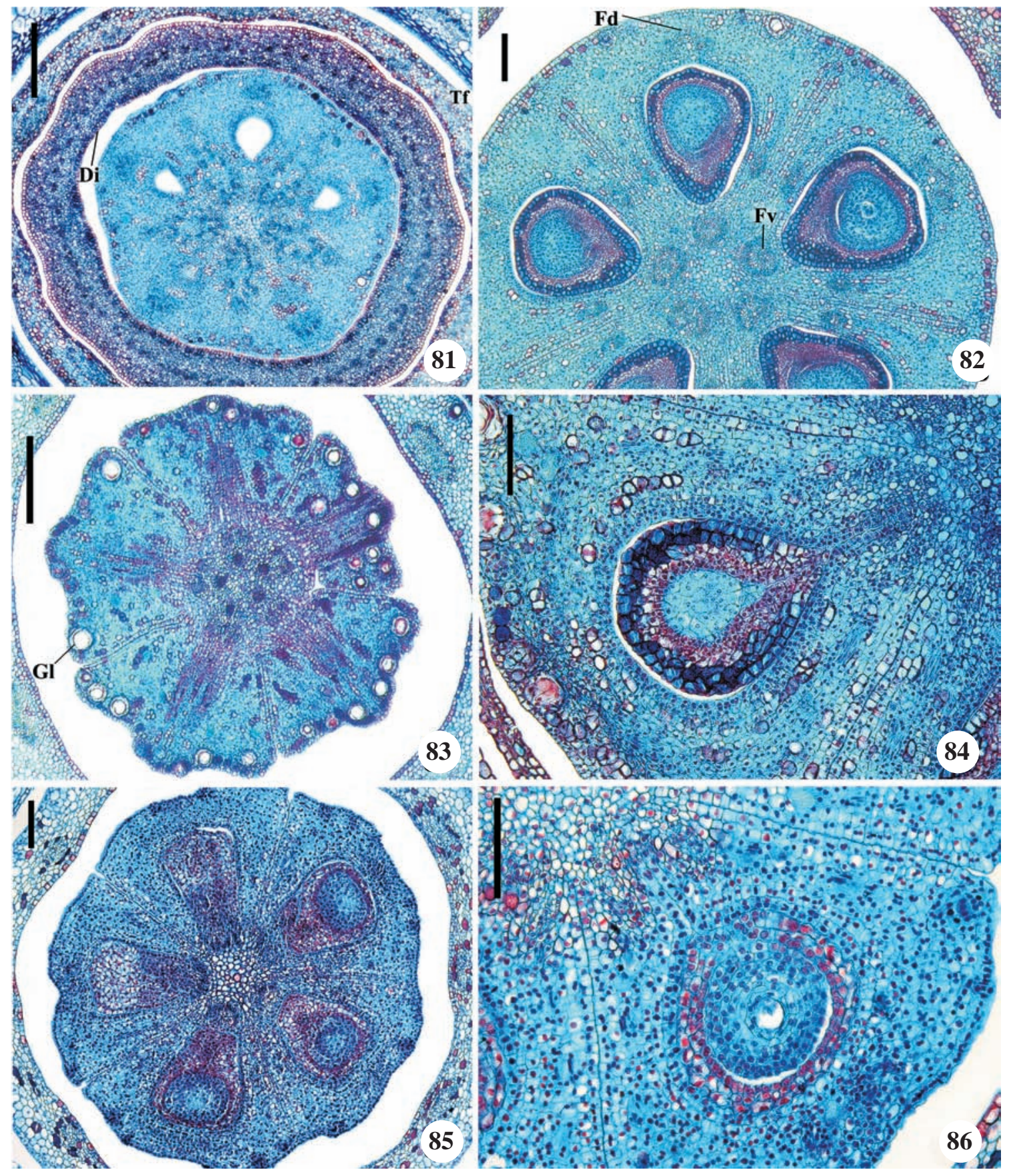

Figuras 81-86. Fotomicrografias de secções transversais de botão floral de Galipea. 81-84. G. dasysperma. 81. Região da base do ovário e do disco. 82. Região mediana do ovário, com feixes carpelares ventrais fundidos. 83. Região do ápice do ovário, com epidermes radiais entre carpelos distintos. 84. Detalhe de carpelo com sutura evidente das epidermes adaxiais, nas região da inserção do óvulo. 85-86. G. jasminiflora. 85. Região do ápice do ovário, com epidermes radiais entre carpelos distintos. 86. Detalhe do carpelo com traços ventrais livres. $(\mathrm{Di}=$ disco; $\mathrm{Fd}=$ feixe dorsal do carpelo; $\mathrm{Fv}=$ feixe ventral do carpelo; Gl = glândula). 18-29. Barra = $500 \mu \mathrm{m}$ (81, 83), $200 \mu \mathrm{m}$ (82, 85), $100 \mu \mathrm{m}$ (84, 86).

Figures 81-86. Photomicrographs of transections of floral buds of Galipea. 81-84. G. dasysperma. 81. Basal region of ovary and disc. 82. Median region of ovary, with fused ventral carpelar bundles. 83. Apical region of ovary, with radial epidermis flanking each carpel. 84. Detail of a carpel with a conspicuous suture of adaxial epidermis, in the region of ovule insertion. 85-86. G. jasminiflora. 85. Apical region of ovary, with radial epidermis between distinct carpels. 86. Detail of a carpel with free ventral traces. $(\mathrm{Di}=$ nectariferous disc; $\mathrm{Fd}=$ dorsal bundle of carpel; $\mathrm{Fv}=$ ventral bundle of carpel; $\mathrm{Gl}=$ gland). Bar $=500 \mu \mathrm{m}(81,83), 200 \mu \mathrm{m}(82,85), 100 \mu \mathrm{m}(84,86)$. 
(figuras 23, 24), e em cada carpelo permanecem na região central do receptáculo alguns feixes que constituirão mais acima os feixes ventrais de carpelo (figuras 26, 27). Na altura em que se diferencia a parte basal dos lóculos, um sifonostelo dissecado permanece bem evidente no centro (figura 33). Em cada carpelo, os feixes mais desenvolvidos são o dorsal e os dois ventrais; estes dois ficam muito próximos um do outro (figuras 27, 84, 86), e em $G$. dasysperma podem inclusive apresentar-se fundidos por certa extensão do ovário (figura 82). Assim, embora os carpelos sejam conatos axial e lateralmente na maior extensão, a vascularização de cada carpelo mantém-se independente da dos carpelos vizinhos desde o receptáculo floral até a base do estilete, que recebe cinco feixes vasculares como ramificações a partir dos feixes carpelares ventrais (figuras 68, 83). Em níveis mais acima, os feixes do estilete se dividem em feixes menores (figuras 52-58, 71).

\section{Discussão}

A ocorrência esporádica de algumas flores hexâmeras em meio a inflorescências portadoras de flores pentâmeras, aqui encontrada em $G$. carinata, tem sido reportada para diversos grupos em Sapindales e outras angiospermas. Todavia, não havia sido encontrada quando da descrição original da referida espécie (Pirani 2004).

Os aspectos gerais da morfologia externa da flor aqui reportados são condizentes com a maioria das descrições existentes na literatura clássica do gênero (e.g. Engler 1874, 1931, Eichler 1878), porém algumas correções e um certo aprimoramento puderam ser agora trazidos com o estudo mais detalhado, sobretudo no plano anatômico, comentados à frente junto aos tópicos adequados. O presente trabalho não realizou análise minuciosa da vascularização floral, mas pode-se afirmar que a maioria dos padrões observados nas espécies aqui estudadas de Galipea diverge apenas em certos pontos do que já foi reportado para outros gêneros da família, como Choisya, Poncirus, Ruta e Citrus (Gut 1966, Guédès 1973), ou vários gêneros de Autantioideae (Tillson \& Bamford 1938), ou Pilocarpus (Souza et al. 2003). Sem dúvida, os pontos divergentes mais notáveis referem-se às peculiaridades observadas nos traços de corola e androceu em Galipea, relacionadas à existência do tubo floral resultante da adnação entre esses dois verticilos, na região proximal da flor, e à existência de alguns estaminódios claramente homólogos a estames esterilizados (alternos a pétalas) e de outros estaminódios opostos a pétalas, que podem ser na realidade apêndices petalares.
O disco hipógino que circunda o ovário é nectarífero, segundo observações de Piedade \& Ranga (1993) em G. jasminiflora. Essas mesmas autoras demonstraram que na flor dessa espécie a maturação dos órgãos reprodutivos é simultânea, mas que ela passa por uma fase masculina (anteras expostas na flor, estilete incluso), que dura cerca de 24 horas, seguida de uma fase feminina (estilete alongando-se até ficar exserto) de mesma duração. Essa configuração floral é característica também das demais espécies de Galipea aqui estudadas, sugerindo a ocorrência de mecanismos florais semelhantes. Além disso, na disposição dos lobos da corola na antese, quando o lobo mais interno fica em posição vertical e os demais tomam posição horizontal, em ângulo reto como o tubo corolino, forma-se uma "plataforma de pouso aos insetos visitantes”, nas palavras de Piedade \& Ranga (1993) para Galipea jasminiflora, na qual se observaram insetos noturnos (geometrídeos e a borboleta Astraptes fulgerator) como os mais eficientes polinizadores desta espécie.

A função nectarífera dos discos e ginóforos encontrados na flor da vasta maioria das Rutaceae tem sido aventada por muitos autores e comprovada para alguns gêneros. Gut (1966) defende essa função com base na vascularização do disco predominantemente por feixes floemáticos. O disco da flor de Pilocarpus pennatifolius Lem. foi descrito por Souza et al. (2005) como nectário de epiderme papilosa, com estômatos e tecido secretor de células diminutas. Nas flores de Galipea ora estudadas não foi possível corroborar essa observação.

Os numerosos feixes observados em Galipea que, partindo do estelo ascendem para irrigar o disco, constituem situação semelhante à observada em Ruta graveolens L. por Guédès (1973). Alguns trabalhos têm abordado a controvérsia sobre origem do disco na família, destacando-se as seguintes hipóteses: 1. o disco das Rutaceae seria um verticilo de carpelos estéreis (Saunders 1934, Moore 1936) ou um apêndice dos carpelos (Guédès 1973); 2. o disco nas flores obdiplostemônes de Aurantioideae (grupo das frutas cítricas) representaria um terceiro verticilo de estames vestigiais (Tillson \& Bamford 1938); 3. o disco seria originado de uma proliferação do eixo floral entre o androceu e o gineceu (Tilak \& Nene 1976), provavelmente com envolvimento de tecidos carpelares também (Gut 1966). Puri (1951) menciona que todas elas podem ocorrer em diferentes táxons de Rutaceae. $\mathrm{O}$ androceu na tribo Galipeeae é haplostêmone com estames alternipétalos, o que inviabiliza a hipótese de transformação de um ciclo de estames em disco na flor dessa tribo. Isso porque 
tal redução teria que ter ocorrido a partir de ancestrais obdiplostêmones, como são os gêneros com dois ciclos de estames na família e na maior parte das plantas da ordem Sapindales. Nessa condição, o ciclo de estames reduzido seria o mais externo e a posição do disco seria extraestaminal (como ocorre em Sapindaceae) e não intraestaminal como acontece em Rutaceae. Os dados de vascularização floral de Galipea não permitem esclarecer a natureza do disco de modo definitivo, mas parecem favorecer a terceira hipótese de origem do disco a partir do receptáculo (e carpelos?), uma vez que os traços que o irrigam são muito numerosos e divergem diretamente do estelo floral, logo no nível abaixo dos traços carpelares, e os carpelos verdadeiros são alternos e não opostos às pétalas. Em Pilocarpus pennatifolius, tradicionalmente colocado na mesma tribo Galipeeae, a localização do disco, sua vascularização e continuidade histológica com a parede do ovário, caracterizam-no como de origem carpelar, segundo Souza et al. (2003). Porém Gut (1966) afirmou para esta mesma espécie, assim como para todas as outras de Rutaceae estudadas por ele, que os discos e ginóforos seriam formações do eixo central da flor, aventando como possível certa participação de tecidos carpelares. Já Guédès (1973) insiste no papel importante do eixo floral na sincarpia, observada pelo menos na base do gineceu em gêneros como Choysia e Ruta, ou prolongada até a sua região mediana, como em Poncirus e Citrus (e poderíamos acrescentar Galipea), mas não na formação do disco, que ele prefere admitir como apêndice ovariano (baseado no fato de os traços do disco serem semelhantes aos carpelares). Nas flores de Galipea, foi observado que na altura em que se diferencia a parte basal dos lóculos do ovário um sifonostelo dissecado permanece bem evidente no centro (figura 33), e isso poderia ser interpretado da maneira descrita acima por Gut (1966): como provável evidência da presença do eixo floral até ali. Contudo esse padrão não diverge do mais geral para gineceu das angiospermas (e.g. Puri 1951), e não encontramos aqui subsídio para a polêmica idéia daquele autor.

A posição dos carpelos em Galipea, antepétalos, é reportada para todos os gêneros com flores isômeras de Rutaceae já estudados (Eichler 1878, Saunders 1934, Tillson \& Bamford 1938, Gut 1966, Guédès 1973, Ramp 1988).

Carpelos peltados e congenitalmente fechados, pelo menos na porção basal, têm sido referidos para numerosos gêneros de Rutaceae, variando na família o grau de união entre eles. Gut (1966) analisou espécies de Choysia, Citrus, Coleonema, Correa, Dictamnus, Evodia, Phellodendron, Pilocarpus, Poncirus, Ptelea,
Ruta, Skimmia e Zanthoxylum e quatro desses gêneros foram estudados também por Guédès (1973). O primeiro autor concluiu que a união entre carpelos é frágil nos membros da subfamília Rutoideae, em contraste com a forte conação radial posgenital observada entre os carpelos das Toddalioideae e Aurantioideae. Segundo esse autor, em Rutoideae, os carpelos ficam unidos entre si apenas na base do gineceu, e devido a um alongamento do eixo central surge a zona apocárpica do gineceu e logo acima dela os estiletes se apresentam unidos posgenitalmente. Isso também foi observado por Souza et al. (2003) em Pilocarpus pennatifolius e, com efeito, parece ser efetivamente verdadeiro para a maioria dos gêneros dessa subfamília (ver Ramp 1988). Porém, Galipea parece ser um caso excepcional em Rutoideae, visto que seus carpelos se apresentam unidos por quase toda a extensão, o que possivelmente se deve à fusão congênita, ao menos em alguma porção dos capelos, exceto na região mediana e superior do ovário, onde as epidermes radiais dos carpelos adjacentes são individualizadas. Graças a essa conformação, os carpelos permanecem bem unidos na antese como se o ovário fosse plenamente sincárpico, formando um fruto do tipo cápsula, em franco contraste com os esquizocarpos que predominam em Rutoideae.

Embora com esse maior grau de sincarpia, o padrão de vascularização do ovário de Galipea diverge pouco da situação mais comum das Rutoideae, em que a vascularização de cada carpelo mantém-se independente da dos carpelos contíguos desde o receptáculo floral até a base do estilete, não havendo fusão de feixes nem perda de feixes. Em Galipea, observou-se padrão semelhante mas com certa fusão dos feixes ventrais dos carpelos, em curta extensão. Assim, considerando também os outros verticilos aqui analisados, de um modo geral, o padrão vascular floral básico proposto por Puri (1951) é mantido.

Ocálice da flor de Galipea éplenamentegamossépalo, com individualização de cinco lobos (sépalas) apenas na parte distal. Já a corola aparentemente tubular da flor de Galipea não é genuinamente gamopétala, mas sim resultante de diferentes estados de adnação/ conação ou coerência/aderência entre o androceu e a corola, observados em três regiões a saber: na porção proximal, está constituído por um verdadeiro tubo floral, resultante da conação dos filetes e da adnação destes às pétalas; na região mediana, a aparência tubulosa decorre da coerência entre as pétalas proporcionada pelo entrelaçamento dos tricomas de sua superfície e pela aderência destas ao tubo estaminal; no terço distal da parte tubular da flor, o mesmo tipo de entrelaçamento de 
indumento condiciona a aderência das pétalas aos filetes e estaminódios livres (i.e., não conatos). Portanto, os diagramas florais de Galipea jasminiflora representados nas obras de Engler (1874) e Baillon (1875) e no livro clássico sobre diagramas de Eichler (1878) estão errôneos ao mostrar e descrever uma corola gamopétala. Por outro lado, nesses três trabalhos a descrição e desenho da união das anteras entre si e aos dois estaminódios que as flanqueiam são bem acurados, estando de acordo com as observações presentes.

Tendo em vista que a condição básica na subtribo Galipeinae é a isostemonia, o fato de gêneros como Ertela Adans. e outros terem duas anteras e três estaminódios alternipétalos é facilmente interpretado. Porém Galipea e alguns outros gêneros de Galipeinae (e.g. Rauia Nees \& Mart.) apresentam cinco (ou mais) estruturas denominadas estaminódios, cuja origem sempre foi intrigante. Com o presente trabalho pôde-se demonstrar que, em Galipea, as três estruturas filiformes colocadas em posição alternada com pétalas são efetivamente estames esterilizados (estaminódios), enquanto as demais (geralmente duas, podendo ser três em algumas espécies) são vascularizadas com traços provenientes de pétalas, podendo tratar-se de apêndices petalares e não de estaminódios epipétalos. Estes dois (ou três) estaminódios especiais dispõem-se opostos à pétala mais externa e a uma pétala adjacente a ela, ou, em G. dasysperma, também a uma pétala adjacente à pétala interna. Nesta última espécie, é muito evidente o surgimento dessas estruturas como expansões adaxial-medianas de pétalas. Aventa-se diante desse fato a possibilidade de situação similar nos demais gêneros de Galipeinae com duas anteras e mais de três estaminódios (onde pelo menos um ou dois são opostos a pétalas): Angostura Roem. \& Schult., Erythrochiton Nees \& Mart., Rauia Nees \& Mart., Raveniopsis Gleason, Sigmatanthus Huber ex Emmerich, Ticorea Aubl. e Toxosiphon Baill. (Kallunki 1992, 1994, 1998, Kallunki \& Pirani 1998, Pirani 1999).

As flagrantes divergências no plano morfoanatômico observadas em $G$. dasysperma convergem com sua posição duvidosa no gênero, já aventada com base em outros caracteres não tratados neste trabalho (e.g. semente pilosas), necessitando-se de uma reavaliação da circunscrição de Galipea, o que deve ser alcançado com análise filogenética.

A aderência ou coerência das margens de peças do perianto por entrelaçamento de tricomas observada em Galipea constituem fenômenos denominados em inglês como "capillinection" (Weberling 1989), já referidos por exemplo para as sépalas de flores de
Tilia L. (Malvaceae). Na antese de flores desse tipo, as sépalas e pétalas geralmente se livram desse tipo de união mútua, porém Weberling (1989) observa que, em alguns casos, a união é tão íntima que as partes do perianto podem permanecer juntas por um período de tempo maior, ou até se desprenderem do resto da flor como uma única peça. Isso é o que efetivamente se nota também na flor das espécies de Galipea, nas quais o tubo formado pelas pétalas aderidas aos filetes permanece coeso e cai inteiro após o início da formação do fruto, mesmo que nessa fase haja alguma separação parcial das pétalas, sobretudo na base, à medida que a estrutura se desidrata e resseca.

Vale ressaltar que a espécie recentemente descrita, G. ramiflora Pirani, tem pétalas bem pouco coerentes entre si e aderentes aos filetes, exceto na fauce, onde são firmemente unidas. Na maior extensão do tubo das flores maduras (sobretudo nas desidratadas em herbário) as pétalas separam-se umas das outras e do tubo que suporta as anteras, que se mantém íntegro (Pirani \& Kallunki 2007).

Tipo análogo de fusão pós-gênita por meio da união dos filetes dos estames que se alternam às pétalas, ou seja, pela adnação entre o verticilo de estames e o de pétalas, resultando na formação de uma corola aparentemente simpétala e tubulosa, foi observado em espécies de Lonchostoma Wikstr. e outros gêneros da família sul-africana Bruniaceae (de posição incerta na base do clado euasterídeas II, no sistema APG II 2003) por Leinfellner (1964). Rohweder (1969 apud Weberling 1989) relata que em alguns gêneros de Commelinaceae (monocotiledônea comelinóide segundo APG II) também ocorre fusão das pétalas indiretamente, por meio da união destas a estames epissépalos (Weberling 1989).

Já em Correa, outro gênero de Rutaceae com flor tubulosa, a constituição morfoanatômica desse atributo apresenta-se diferentemente. Na espécie australiana Correa speciosa (tribo Boronieae, Rutoideae), já mencionada, não há qualquer adnação entre corola e androceu, as pétalas são livres na base e, na região tubular da corola, na sutura entre pétalas adjacentes persistem duas camadas de epiderme e ainda uma camada de cutícula entre elas, o que caracteriza uma falsa simpetalia (Troll 1937, Hartl 1957, Weberling 1989).

Assim, fica claro que em diferentes grupos de Rutaceae, e mesmo dentre as angiospermas, a evolução de flores tubulosas ocorreu por modos distintos e variados, com expressivo grau de homoplasias. Pressões seletivas diversas podem favorecer um tipo geral de flor tubulosa, cujas prováveis vantagens adaptativas sejam uma restrição maior a visitantes pilhadores de recursos 
como néctar (e pólen no caso de gêneros com anteras inclusas no tubo corolino), ou uma conformação mais efetiva na garantia de sucesso na polinização, ou ainda na proteção aos órgãos reprodutivos internos da flor. Entretanto, os caminhos ontogenéticos que levam a esse modelo estrutural geral podem ser bem semelhantes em gêneros sem parentesco próximo (homoplasias), ou podem ser bem diferentes mesmo entre gêneros de uma mesma família. No caso de Rutaceae constatamse agora as duas possibilidades. Primeiro, a filogenia apresentada por Groppo et al. (2008) indica forte relação de parentesco entre Galipea e Angostura, Conchocarpus, Ravenia e Sigmatanthus, que formam o único clado com flores tubulosas dentro de um clado maior assim constituído: (Choisya, Pilocarpus, Ptelea (Balfourodendron, Helietta (Esenbeckia, Metrodorea)) (Agathosma, Coleonema) (Angostura, Conchocarpus, Galipea, Ravenia, Sigmatanthus) (Adiscanthus, Hortia)), onde todos os demais possuem flores abertas (não tubulosas), situação de resto predominante na família como um todo. Isso pode sugerir que pelo menos alguns dos aspectos morfoanatômicos relacionados à condição de flor tubulosa, descritos no presente trabalho, sejam compartilhados por todos ou alguns daqueles cinco gêneros, como homologias (sinapomorfias - homologia primária sensu Pinna 1991). Porém, não há dados anatômicos disponíveis para elucidar isso por ora. Por outro lado, os clados relacionados aos cinco gêneros supra-citados da tribo Galipeeae não têm proximidade filogenética com Correa (tribo Boronieae), que emergiu internamente ao clado-irmão daquele supra-descrito (Groppo et al. 2008), e portanto as diferenças morfoanatômicas comentadas mostram que o aspecto tubuloso da flores constitui semelhança apenas superficial, que nem deve ser tratado como um paralelismo. Torna-se óbvia assim a necessidade de mais estudos dessa natureza nessa família, pois só assim será possível contar com estados de caráter bem definidos para elaboração de análises filogenéticas confiáveis e para estabelecer conjecturas bem embasadas sobre evolução floral no grupo.

Finalmente, embora Gut (1966) tenha afirmado que a vascularização em Rutaceae é muito complicada e que qualquer interpretação da natureza morfológica de suas partes florais seria muito problemática caso baseada apenas em estudo de anatomia vascular, os dados dos trabalhos anatômicos posteriores ao dele, assim como estes reportados para Galipea, demonstram o incontestável papel da anatomia para o conhecimento acurado da estrutura floral no grupo e para a resolução de questões acerca de homologia e filogenia.
Agradecimentos - A Jacquelyn Kallunki, por fornecer as flores fixadas de Galipea dasysperma e pelas muitas discussões sobre morfologia e sistemática em Galipeeae. A Gisele R. Oliveira Costa, pelo preparo das lâminas com as secções anatômicas e pelo inestimável auxílio na tomada de imagens ao fotomicroscópio. Ao Klei Rodrigo Sousa, pelo bonito trabalho a nanquim sobre os desenhos originais do primeiro autor na figuras 1 a 17. Ao Dr. Richard Winkworth, pela correção do abstract. Ao CNPq, pelo apoio financeiro ao projeto de pesquisa, por meio de bolsas de produtividade ao primeiro e terceiro autores e bolsa de Iniciação Científica ao segundo autor.

\section{Referências bibliográficas}

APG II. 2003. An update of the Angiosperm Phylogeny Group classification for the orders and families of flowering plants: APG II. Botanical Journal of the Linnean Society 141:399-436.

BAILLON, H. 1875. Natural history of plants. L. Reeve \& Company, London, v.4.

BELTRATI, C.M. 1991. Estudo morfo-anatômico das sementes e plântulas de Esenbeckia febrifuga (St. Hil.) A. Juss. ex Mart. (Rutaceae). Naturalia 16:161-169.

EAMES, A.J. 1961. Morphology of the angiosperms. McGraw-Hill Book Company, New York.

EICHLER, A.W. 1878. Blütendiagramme. Wilhelm Engelmann, Leipzig. Teil 2.

ENGLER, H.G.A. 1874. Rutaceae. In Flora brasiliensis (C.P.F. Martius \& A.G. Eichler, eds.). Friedrich Fleischer, Leipzig, v.12, pars 2, p.75-196, tabs.14-39.

ENGLER, H.G.A. 1931. Rutaceae. In Die natürlichen Pflanzenfamilien (H.G.A. Engler \& K.A.E. Prantl, eds.). Wilhelm Engelmann, Leipzig, v.19, ed.2, p.187-359.

FORD, E.S. 1942. Anatomy and histology of the Eureka lemon. Botanical Gazette 104:288-305.

GROPPO, M., PIRANI, J.R., SALATINO, M.L., BLANCO, S.R. \& KALLUNKI, J.A. 2008. Phylogeny of Rutaceae based on two non-coding regions from cpDNA. American Journal of Botany 95:985-1005.

GUÉDÈS, M. 1973. Carpel morphology and axis-sharing in syncarpy in some Rutaceae, with further comments on "New Morphology". Botanical Journal of the Linnean Society 66:55-74.

GUT, B.J. 1966. Beiträge zur Morphologie des Gynoeciums und der Blütenachse einiger Rutaceen. Botanisches Jarhbücher Systematische 85:151-247.

HARTL, D. 1957. Die Pseudosympetalie von Correa speciosa (Rutaceae) und Oxalis tubiflora (Oxalidaceae). Abhandlungen der MathematischNaturwissenschaftlichen Klasse, Akademie der Wissenschaften und der Literatur, Mainz, 2:1-13.

JOHANSEN, D.A. 1940. Plant microtechnique. McGrawHill Book Company, New York. 
KALLUNKI, J.A. 1992. A revision of Erythrochiton sensu lato (Cuspariinae, Rutaceae). Brittonia 44:107-139.

KALLUNKI, J.A. 1994. Revision of Raputia Aubl. (Cuspariinae, Rutaceae). Brittonia 46:279-295.

KALLUNKI, J.A. 1998. Revision of Ticorea Aubl. (Rutaceae, Galipeinae). Brittonia 50:500-513.

KALLUNKI, J.A. \& PIRANI, J.R. 1998. Synopses of Angostura Roem. \& Schult. and Conchocarpus J. C. Mikan. Kew Bulletin 53:257-334.

KRAUS, J. \& ARDUIN, M. 1997. Manual básico de métodos em morfologia vegetal. Edur, Seropédica.

LEINFELLNER, W. 1964. Über die falsche sympetalie bei Lonchostoma und anderen Gattungen der Bruniaceen. Österreichische Botanische Zeitschrift 111:345-353.

MARQUETE, O. 1981. Anatomia e vascularização foliar e floral de Pilocarpus organensis Occhioni \& Rizzini (Rutaceae). Arquivos do Jardim Botânico do Rio de Janeiro 25:117-159.

MOORE, J.A. 1936. Floral anatomy and phylogeny in the Rutaceae. New Phytologist 35:318-322.

PINNA, M.C.C. 1991. Concepts and tests of homology in the cladistic paradigm. Cladistics 7:317-338.

PIEDADE, L.H. \& RANGA, N.T. 1993. Ecologia da polinização de Galipea jasminiflora Engler (Rutaceae). Revista Brasileira de Botânica 16:151-157.

PIRANI, J.R. 1999. Estudos taxonômicos em Rutaceae do Brasil: Revisão de Helietta e Balfourodendron (Pteleinae). Análise cladística de Pteleinae. Sinopse de Rutaceae do Brasil. Tese de Livre-docência, Universidade de São Paulo, São Paulo.

PIRANI, J.R. 2002. Rutaceae. In Flora Fanerogâmica do Estado de São Paulo (M.G.L. Wanderley, G.J. Shepherd, A.M. Giulietti, T.S. Melhem, V. Bittrich \& C. Kameyama, eds.). Fapesp, Hucitec, São Paulo, v.2, p. 281-308.

PIRANI, J.R. 2004. Three new species of Galipea (Rutaceae, Galipeinae) from Brazil. Botanical Journal of the Linnean Society 144:365-373.
PIRANI, J.R. \& KALLUNKI, J.A. 2007. Two new species of Galipea (Rutaceae, Galipeae) from Bolivia, Ecuador, and Peru. Brittonia 59:343-349.

PURI, V. 1951. The role of floral anatomy in the solution of morphological problems. The Botanical Review 17:471-553.

RAMP, E. 1988. Struktur, Funktion und systematische Bedeutung des Gynoeciums bei den Rutaceae und Simaroubaceae. PhD Dissertation, Universität, Zürich.

SAUNDERS, E.R. 1934. On carpel polymorphism VI. Annals of Botany 48:643-692.

SOUZA, L.A., MOURÃO, K.S.M., MOSCHETA, I.S. \& ROSA S.M. 2003. Morfologia e anatomia da flor de Pilocarpus pennatifolius Lem. (Rutaceae). Revista Brasileira de Botânica 26:175-184.

SOUZA, L.A., MOSCHETA, I.S., MOURÃO, K.S.M. \& ROSA S.M. 2004. Morphology and anatomy of the flowers and anthesis of Metrodorea nigra St. Hil. (Rutaceae). Brazilian Archives of Biology and Technology 47:107-112.

SOUZA, A., MOURÃO, K.S.M. \& SOUZA, L.A. 2005. Morfologia e anatomia do fruto e da semente em desenvolvimento de Pilocarpus pennatifolius Lem. (Rutaceae). Revista Brasileira de Botânica 28:745-754.

TILAK, V.D. \& NENE, P.M. 1976. The disc in the Rutaceae. Journal of the University of Bombay 45:49-53.

TILAK, V.D. \& NENE, P.M. 1978. Floral anatomy of the Rutaceae. Indian Journal of Botany 1:83-90.

TILLSON, A.H. \& BAMFORD, R. 1938. The floral anatomy of the Aurantioideae. American Journal of Botany 25:780-793.

TROLL, W. 1937. Vergleichende Morphologie der höheren Pflanzen. Königstein, Berlin, v.1.

WEBERLING, F. 1989. Morphology of flowers and inflorescences. Cambridge University Press, Cambridge.

YAMAZAKI, T. 1988. Floral anatomy of the genus Zanthoxylum L. Journal of Japanese Botany 63:7-16. 